Juan Pablo Ibañez

\title{
Modelagem micro-mecânica discreta de solos residuais
}

\section{TESE DE DOUTORADO}

DEPARTAMENTO DE ENGENHARIA CIVIL

Programa de Pós-Graduação em Engenharia Civil 


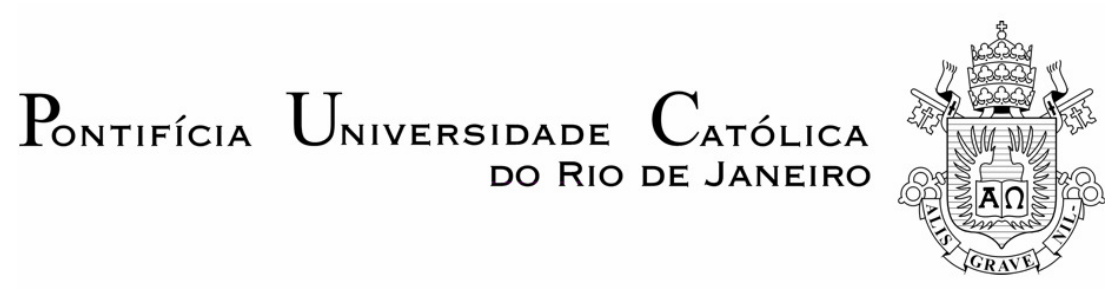

Juan Pablo Ibañez

\section{Modelagem micro-mecânica discreta de solos residuais}

Tese apresentada ao Programa de Pós-graduação em Engenharia Civil da PUC-Rio como requisito parcial para obtenção do título de Doutor em Engenharia Civil.

Orientador: Prof. Tácio Mauro Pereira De Campos

Co-orientador: Prof. Eurípedes do Amaral Vargas Junior

Rio de Janeiro, abril de 2008 


\section{Pontifícia Universidade C Católica $_{\text {and }}$ \\ DO RIO DE JANEIRO}

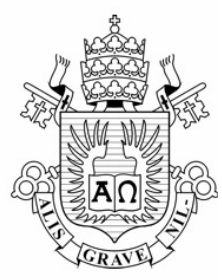

Juan Pablo Ibañez

Modelagem micro-mecânica discreta de solos residuais

Tese apresentada como requisito parcial para obtenção do título de Doutor pelo Programa de Pós-Graduação em Engenharia Civil da PUC-Rio. Aprovada pela Comissão Examinadora abaixo assinada.

Prof. Tácio Mauro Pereira De Campos

Presidente/Orientador

Departamento de Engenharia Civil - PUC-Rio

Prof. Eurípedes do Amaral Vargas Junior Departamento de Engenharia Civil - PUC-Rio

Prof. Luiz Fernando Campos Ramos Martha Departamento de Engenharia Civil - PUC-Rio

Prof. Roberto Francisco de Azevedo UFV-MG

Prof. Fernando Antônio Medeiros Marinho

USP

Prof. Leonardo José do Nascimento Guimarães

UFPE

Prof. José Eugênio Leal

Coordenador Setorial do

Centro Técnico Científico - PUC-Rio

Rio de Janeiro, 18 de abril de 2008 
Todos os direitos reservados. É proibida a reprodução total ou parcial do trabalho sem autorização da universidade, do autor e do orientador.

\section{Juan Pablo Ibañez}

Graduou-se em Engenharia Civil na UBA (Universidad de Buenos Aires, Argentina) em 2000. Em 2001 cursou o 'Master internacional' em mecânica dos solos e engenharia de fundações no CEDEX (Centro de estudios y experimentación de obras públicas) de Madri, Espanha. Em 2003 obteve o título de Mestre em Engenharia Civil no programa oferecido pelo Departamento de Engenharia Civil da PUC-Rio. Atualmente se desempenha como analista no laboratório de computação gráfica Tecgraf/PUC-Rio.

Ficha Catalográfica

Ibañez, Juan Pablo

Modelagem micro-mecânica discreta de solos residuais / Juan Pablo Ibañez ; orientador: Tácio M. P. De Campos ; co-orientador: Eurípedes A. Vargas Jr. -2008.

2 v. : il. ; $30 \mathrm{~cm}$

Tese (Doutorado em Engenharia Civil)Pontifícia Universidade Católica do Rio de Janeiro, Rio de Janeiro, 2008.

Inclui bibliografia

1. Engenharia civil - Teses. 2. Solos residuais. 3. Método dos elementos discretos. 4. Modelagem numérica. 5. Análise micro-mecânica. I. De Campos, Tácio M. P. II. Vargas Jr., Eurípedes A. III. Pontifícia Universidade Católica do Rio de Janeiro. Departamento de Engenharia Civil. IV. Título.

CDD: 624 


\section{Agradecimentos}

A Deus meu Senhor, pela sua fidelidade e misericórdia, as quais nunca faltaram nestes anos aqui no Brasil.

A Verônica, minha esposa e companheira, pelo seu doce amor, amizade e constante apóio.

A Sofia e Micaela, minhas princesinhas, presentes de Deus que enchem minha vida de amor e alegria.

A minha família em Argentina, pais, avó, irmão, sogra, cunhadas, tios, e restante da família e amigos que se preocuparam em manter os laços de amizade e carinho na distância.

Ao professor Tácio, pela orientação recebida, pela confiança depositada em mim ao longo do programa de doutorado, e pela possibilidade de pertencer ao seu grupo de pesquisa no marco do projeto PRONEX.

Ao professor Vargas, pela orientação recebida, pelo compromisso com a minha pesquisa e pelos diversos apoios ao meu desenvolvimento profissional.

Aos professores membros da banca, pela disposição para analisar esta tese e pelos aportes e sugestões dadas.

A Márcio Santi, pela oportunidade de pertencer à família do Tecgraf, e pela boa vontade e apóio manifestos para com a minha pesquisa.

Ao João Luiz e à Raquel, meus colegas discretos, pela sua valiosa ajuda no desenvolvimento da minha pesquisa.

Aos colegas do Tecgraf pelo convívio cordial no dia a dia e por todo o aprendizado com eles.

Ao Andrezinho, pela sua ajuda desinteressada que facilitou meu convívio com a linguagem Lua.

A CNPq e CAPES, pelo apóio financeiro nos primeiros anos do doutorado.

Ao TECGRAF, pelo apóio financeiro, e por me oferecer um espaço de trabalho, aprendizado e convívio que resultou um apóio fundamental para a minha pesquisa.

A todas as pessoas vinculadas ao Departamento de Engenharia Civil, pelo trato afetuoso e respeitoso que fizeram o convívio cordial e agradável. 


\section{Resumo}

Ibañez, Juan Pablo; De Campos, Tácio Mauro Pereira. Modelagem micromecânica discreta de solos residuais. Rio de Janeiro, 2008. 394p. Tese de Doutorado - Departamento de Engenharia Civil, Pontifícia Universidade Católica do Rio de Janeiro.

O presente trabalho de pesquisa estuda a modelagem numérica de solos residuais no que se refere ao seu comportamento mecânico, a partir da análise micro-mecânica, utilizando como ferramenta de modelagem o método dos elementos discretos (MED), o qual permite a representação do solo como meio particulado 2D por meio de elementos discretos circulares. Diversos são os fenômenos micro e macro-estruturais presentes nos solos residuais, os quais condicionam sua resposta mecânica, podendo-se mencionar a dupla estrutura e dupla porosidade, a presença de uma matriz argilosa, a condição não saturada, a cimentação e quebra de grãos, e a presença de pequenos blocos de rocha não alterada. A partir do estudo destes fenômenos foram propostas formulações matemáticas que os descrevem, as quais foram implementadas no código de elementos discretos DEMlib. Após a calibração e validação do programa de análise implementado, a influência de cada um destes fenômenos na resposta mecânica do solo foi estudada pela simulação dos ensaios edométrico e de cisalhamento direto em amostras discretas com compacidade variada, criticando os resultados e obtendo conclusões. Em seguida estes fenômenos foram estudados de forma combinada no intuito de reproduzir a resposta de alguns solos residuais jovens e maduros. Encerrando o trabalho foram resumidas as conclusões obtidas e apontadas sugestões para um aprofundamento e desenvolvimentos subseqüentes da linha de pesquisa implementada.

\section{Palavras-chave}

Solos não saturados, Solos residuais, Método dos elementos discretos, Modelagem numérica, Análise micro-mecânica. 


\section{Abstract}

Ibañez, Juan Pablo; De Campos, Tácio Mauro Pereira. Discrete micromechanical modeling of residual soils. Rio de Janeiro, 2008. 394p. PhD. Thesis - Departament of Civil Engeneering, Pontifícia Universidade Católica do Rio de Janeiro.

The present research studies the numerical modeling of the mechanical behavior of residual soils, by a micro-mechanical analysis, using as modeling tool the discrete elements method (DEM), which allows the representation of the soil as 2D particle assembly of circular discrete elements. There are several micro and macro structural phenomena present in residual soils, which determine its mechanical response: double structure and double porosity of soil mass, the presence of a clay-like matrix, partially saturated condition, grain cementation, grain crushing, and the presence of small blocks of not-weathered parental rock. Based on the study of these phenomena, mathematical formulations have been proposed in order to describe them, which have been implemented in the DEMlib discrete elements code. After calibration and validation of the implemented analysis program, the influence of each phenomena in soil response was studied by simulating edometrical and direct shear tests in discrete samples with several densities, criticizing the results and getting conclusions. Afterwards, these phenomena were studied in a combined way in order to reproduce the response of some young and mature residual soils. To finish up this work the conclusions obtained have been summarized and suggestions for deepening and further developing of the implemented research line have been stated.

\section{Keywords}

Unsaturated soils, Residual soils, Discrete elements method, Numerical Modeling, Micro-mechanical analysis. 


\section{Sumário}

1. Introdução ao Objeto de Pesquisa 25

2. Caracterização dos Solos Residuais: Gênese, Composição e 29 Comportamento Observado

2.1. Gênese dos solos residuais 29

2.1.1. Os processos intempéricos $\quad 29$

2.1.2. Intemperismo físico 34

2.1.3. Intemperismo químico 36

2.1.4. Perfil de intemperismo 38

2.1.5. Grau de intemperismo $\quad 40$

2.2. Composição dos solos residuais 41

2.2.1. Mineralogia dos solos residuais 42

2.2.2. Formação da estrutura residual 43

2.2.3. Estrutura dupla dos solos residuais 44

2.3. Comportamento dos solos residuais 48

2.3.1. Influência da estrutura residual 48

2.3.2. Influência da anisotropia $\quad 58$

2.3.3. Influência da resistência dos grãos 61

2.3.4. Influência da compacidade 63

2.3.5. Influência do grau de saturação 64

2.3.6. Influência do grau de intemperismo 69

3. Modelagem Micro-Mecânica Discreta de Solos Residuais 71

$\begin{array}{ll}\text { 3.1. Modelagem contínua e discreta } & 71\end{array}$

3.1.1. Modelagem mecânica 72

3.1.2. Modelagem micro-mecânica 76

3.2. Fundamentos do método dos elementos discretos (MED) 82

3.2.1 Representação de blocos e partículas 82

3.2.2. Representação do contato 83

$\begin{array}{lll}\text { 3.2.3. } & \text { Algoritmo de solução } & 83\end{array}$

3.2.4. Perspectivas de desenvolvimento $\quad 84$

3.3. Modelos de partículas em geotecnia $\quad 86$

3.3.1. Modelagem de ensaios laboratoriais $\quad 86$

\begin{tabular}{ll} 
3.3.2. & Modelagem de meios rochosos \\
\hline
\end{tabular}

3.3.3. Modelagem de meios particulados não saturados $\quad 87$

3.3.4. Modelagem de quebra de grãos 88

3.4. Biblioteca DEMlib $\quad 89$

3.4.1. Classes e objetos $\quad 90$

3.4.2. Algoritmo de relaxação dinâmica 92

3.4.3. Estabilidade e convergência 95

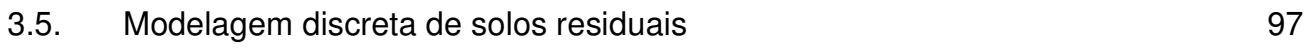

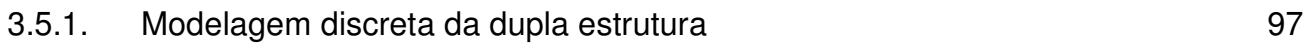

3.5.2. Modelagem discreta das características granulométricas 98

3.5.3. Modelagem discreta dos fenômenos macro-estruturais 99

3.5.4. Modelagem discreta dos fenômenos de fluxo 100

3.6. Outras aplicações da modelagem discreta usando DEMlib 100 
4. Formulações Micro-Mecânicas Discretas 102

4.1. Modelagem de grumos argilosos 103

4.1.1. Formulação do problema de adensamento radial 103

4.1.2. Solução da equação de adensamento radial 107

4.1.3. Solução com variáveis adimensionais 110

4.1.4. Implementação numérica do elemento grumo 114

4.1.5. Validação da formulação implementada 120

4.2. Modelagem da cimentação de grãos 124

4.2.1. Formulação da cimentação de contato 124

4.2.2. Implementação da cimentação de contato 126

4.2.3. Validação da formulação implementada 127

4.3. Modelagem da ligação rochosa $r$

4.3.1. Formulação da ligação rochosa $\quad 130$

4.3.2. Implementação da ligação rochosa 132

4.3.3. Validação da formulação implementada 133

4.4. Modelagem da quebra de grãos 135

4.4.1. Formulação do mecanismo de quebra 135

4.4.2. Implementação da quebra de grãos 137

4.4.3. Validação da formulação implementada 140

4.5. Modelagem do fluxo não saturado 142

4.5.1. Formulação do fenômeno de fluxo não saturado 143

4.5.2. Implementação do fluxo não saturado 157

4.5.3. Validação da formulação implementada 159

4.6. Modelagem do fenômeno expansivo 161

4.6.1. Expansão em solos 161

4.6.2. O fenômeno da expansão 163

4.6.3. Modelagem do mecanismo de expansão 171

4.6.4. Implementação do mecanismo de expansão 174

4.6.5. Validação da formulação implementada 176

4.7. Melhorias na interface gráfica do programa de análise 179

5. Validação do Modelo de Análise Micro-Mecânica 185

5.1. Critérios para a validação do modelo 185

5.1.1. Roteiro de validação 185

5.1.2. Ensaio de referência: cisalhamento direto 186

5.1.3. Outras simulações do ensaio de cisalhamento direto usando MED 190

5.2. Calibração dos parâmetros do programa 194

5.2.1. Rigidez normal (kn) 194

5.2.2. Rigidez tangencial (ks) 196

5.2.3. Amortecimento (Cn, Cs) 197

5.2.4. Massa das paredes (mw) 198

5.3. Calibração do ensaio de referência 199

5.3.1. Influência da representação do solo 199

5.3.2. Influência do índice de vazios da amostra 203

5.3.3. Influência da separação da caixa 205

5.3.4. Influência da parte da caixa que desloca 208

5.4. Validação do programa 211

5.4.1. Resultados dos ensaios de validação 211

5.4.2. Crítica dos resultados obtidos 221

5.4.3. Refinamento da distribuição granulométrica 226 


\section{Simulação dos Fenômenos Micro-Mecânicos presentes em Solos 233}

Residuais

6.1. Objetivos das simulações 233

6.2. Quebra de grãos 234

6.2.1. Ensaio edométrico 235

6.2.2. Campanha de ensaios de cisalhamento direto 238

6.2.3. Resultados da campanha de ensaios 243

6.2.4. Análise dos resultados 260

6.3. Cimentação de grãos 265

6.3.1. Ensaio edométrico 266

6.3.2. Campanha de ensaios de cisalhamento direto 272

6.3.3. Resultados da campanha de ensaios 278

6.3.4. Análise dos resultados 293

6.4. Forma dos grãos 296

6.4.1. Ensaio edométrico 297

6.4.2. Campanha de ensaios de cisalhamento direto 298

6.4.3. Resultados da campanha de ensaios 298

6.4.4. Análise dos resultados 303

6.5. Grumos argilosos 305

6.5.1. Ensaio edométrico 306

6.5.2. Campanha de ensaios de cisalhamento direto 310

6.5.3. Resultados da campanha de ensaios 311

6.5.4. Análise dos resultados 319

6.6. Condição não saturada 322

6.6.1. Ensaio edométrico 323

6.6.2. Campanha de ensaios de cisalhamento direto 328

6.6.3. Resultados da campanha de ensaios 329

$\begin{array}{lll}\text { 6.6.4. Análise dos resultados } & 336\end{array}$

6.7. Condição não saturada e grumos argilosos 341

$\begin{array}{ll}\text { 6.7.1. Ensaio edométrico } & 341\end{array}$

6.7.2. Campanha de ensaios de cisalhamento direto 343

$\begin{array}{ll}\text { 6.7.3. Resultados da campanha de ensaios } & 343\end{array}$

$\begin{array}{lll}\text { 6.7.4. Análise dos resultados } & 346\end{array}$

7. Simulação do Comportamento de Solos Residuais 348

7.1. Comportamento mecânico de solos residuais 348

7.2. Simulação de solos residuais jovens 356

7.2.1. Montagem das amostras 356

7.2.2. Ensaio edométrico 357

7.2.3. Ensaio de cisalhamento direto 360

7.2.4 Análise dos resultados 365

7.3. Simulação de solos residuais maduros 369

7.3.1. Montagem das amostras 369

7.3.2. Ensaio edométrico 370

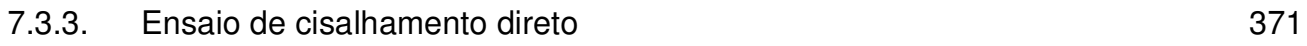

$\begin{array}{lll}\text { 7.3.4. } & \text { Análise dos resultados } & 373\end{array}$

$\begin{array}{lll}\text { 7.4. } & \text { Conclusões } & 374\end{array}$

8. Considerações finais $\quad 375$

$\begin{array}{ll}\text { Referências Bibliográficas } & 386\end{array}$ 


\section{Lista de Figuras}

\section{Capítulo 1}

$\begin{array}{lll}\text { Figura } 1.1 & \text { Roteiro da pesquisa. } & 28\end{array}$

\section{Capítulo 2}

Figura 2.1 Influência do clima na formação de perfis residuais: a) Climas úmidos e desérticos no mundo; b) Regiões quentes e temperadas no mundo; c) Características dos perfis residuais para cada região climática (Strakhov, 1967).

Figura 2.2 Influência do clima global na formação de argilominerais (Uehara, 32 1982).

Figura 2.3 Perfil de intemperismo: a) rocha metamórfica; b) rocha ígnea 38 intrusiva. (adaptado de Deere \& Patton, 1971).

Figura 2.4 Classificação da ISRM para um perfil de alteração (Little, 1969; 39 ISRM, 1981).

Figura 2.5 Processo de formação dos solos residuais. 41

Figura 2.6 Cristalização e alteração para uma andesita (Bowen, 1928 \& 42 Arnold, 1984).

Figura $2.7 \quad$ a) Distribuição do volume de poros de duas amostras de bentonita 45 compactada (Lloret et al, 2003); b) Representação dos dois níveis estruturais.

Figura 2.8 $\quad$ Arranjos micro e macro-estruturais (Collins, 1985). 46

Figura 2.9 Representação esquemática dos níveis estruturais. 48

Figura 2.10 Comportamento do modelo de dupla estrutura no plano p-s. 49

Figura 2.11 Comportamento observado de solos residuais no ensaio triaxial: $\quad 50$

Figura 2.12 a) Características físicas de solo laterítico (1m) e saprolítico $(5 \mathrm{~m}) ; \quad 51$

b) Curva característica dos solos (Futai et al, 2004).

Figura 2.13 Ensaio triaxial com sucção controlada: a) solo jovem; b) solo 52 maduro (Futai et al, 2004).

Figura 2.14 Imagem de microscopia eletrônica de uma areia cimentada: a) 53 Arranjo dos grãos e incrustações cimentíceas; b) Detalhe de cimentação (Cuccovillo \& Coop, 1997).

Figura 2.15 Esquema de compressão simples de solo fraca e altamente 54 cimentado.

Figura 2.16 Esquema dos modos de cisalhamento de solos estruturados. 55

Figura 2.17 Ensaio triaxial de calcarenita natural (Coop \& Atkinson, 1993). 55

Figura 2.18 Mecanismo de colapso para areias metaestáveis (Knight, 1961). 56

Figura 2.19 Índice B em função da tensão isotrópica p no estado crítico para 62 um solo residual de granito (Lee \& Coop, 1995).

Figura 2.20 Relação entre a densidade do solo e a resistência ao 63 cisalhamento, para um solo residual de andesita (Howatt, 1988).

Figura 2.21 Influência da sucção no contato entre grãos de solo. 65

Figura 2.22 Curva característica do solo (sucção x umidade volumétrica). 65 
Figura 2.23 Critério de ruptura de Mohr-Coulomb no espaço $(\tau, \sigma, s) \quad 66$ modificado por Frendlund et al (1978).

Figura 2.24 a) Evolução da coesão aparente com a sucção; b) Envoltória de resistência não linear para estados não saturados (Lopes et al, 2007).

Figura 2.25 Fenômenos de inchamento e colapso sob umedecimento do solo.

\section{Capítulo 3}

$\begin{array}{lll}\text { Figura 3.1 } & \text { Diferentes meios e suas descontinuidades. } & 72\end{array}$

Figura 3.2 Três escalas de modelagem de argilas (Murad \& Cushman, 1996). 78

Figura 3.3 Modelo bimodal para argilas (Murad et al, 2001). 80

Figura 3.4 Modelo bimodal para meios porosos não saturados (Chateau \& 80 Dormieux, 2002).

Figura 3.5 a) Contato entre elementos e forças de contato geradas; b) 83 Rigidez tipo mola-amortecedor.

Figura 3.6 Ciclo de cálculo do algoritmo de Relaxação Dinâmica.

Figura 3.7 Interface gráfica original do código de elementos discretos Sand. 89

Figura $3.8 \quad$ Classe Block e derivadas. $\quad 90$

Figura 3.9 Classe Wall e derivadas. $\quad 90$

Figura 3.10 Classe Link e derivadas. $\quad 91$

$\begin{array}{lll}\text { Figura 3.11 Classe Damping e derivadas. } & 91\end{array}$

Figura 3.12 Forças e momentos atuantes em dois elementos discretos em 92 contato.

Figura 3.13 Contatos por superposição: a) $\Delta n$; b) $\Delta s$. 94

Figura 3.14 Ciclo de cálculo por relaxação dinâmica. $\quad 94$

Figura 3.15 Simulação discreta da formação de um domo salino. 101

\section{Capítulo 4}

Figura 4.1 Elemento grumo representado por um disco 2D. a) Grumo sob a ação de uma carga uniformemente distribuída; b) Elemento diferencial de grumo.

Figura 4.2 Funções de Bessel de primeira classe de ordem zero $J_{0}\left(\alpha_{i} r\right)$, para as seis primeiras raízes.

Figura 4.3 Funções de Bessel de primeira classe de ordem um $J_{1}\left(\beta_{i} r\right)$, para as seis primeiras raízes.

Figura 4.4 Distribuição das poro-pressões normalizadas $\bar{u}$ no disco.

Figura 4.5 Distribuição do grau de adensamento $U r$ no disco. 112

Figura 4.6 Evolução do grau de adensamento médio Urm . 112

Figura 4.7 Evolução do deslocamento radial normalizado $\delta_{r}^{n}$. 113

Figura 4.8 Volume de água normalizado $V_{w}^{n}$ cedido em função do fator de 114

Figura 4.9 Ajuste exponencial dos deslocamentos radiais normalizados no grumo. 
Figura 4.10 Ajuste exponencial do volume de água normalizado cedido ao meio.

Figura 4.11 a) Forças de contato $f c_{i}^{n}$ e de sucção $f s_{i}^{n}$ no elemento grumo num instante $n$; b) Carregamento equivalente $p_{0}^{n}$ como condição de contorno do elemento.

Figura 4.12 Adensamentos no grumo para carregamentos diferidos no tempo.

Figura 4.13 Adensamento sob carregamento variável. Deslocamento radial. 118

Figura 4.14 Estrutura de dados para o cálculo dos estágios de adensamento 120 do grumo.

Figura 4.15 Geometria do exemplo de validação.

$\begin{array}{lll}\text { Figura 4.16 Carga de adensamento teórica e iterativa. } & 121\end{array}$

Figura 4.17 Curva de adensamento para $q=100 . \quad 121$

Figura 4.18 Curva de adensamento semi-logaritmica para $q=100 . \quad 122$

Figura 4.19 Curva de adensamento para os estágios $q=100$ e q = 300 . 122

Figura 4.20 Compressão confinada de solo com grumos: a) Configuração inicial; b, c, d) Configurações durante o adensamento; e) Configuração final; f) Configuração final para o mesmo solo sem grumos.

Figura 4.21 Caráter pontual da cimentação entre grãos de solo.

Figura 4.23 Exemplo de validação: a) Solo cimentado; b) Solo não cimentado.

Figura 4.24 Perfil de alteração. Blocos de rocha presentes na massa residual.

Figura 4.25 Modelo de viga de conexão. Esforço normal, cisalhante e momento.

Figura 4.26 Viga de conexão. Geometria, esforços atuantes e campo de tensões.

Figura 4.27 Critério de ruptura de Coulomb. Parâmetros do critério.

Figura 4.28 Ensaio de compressão confinada: a) Geometria inicial; b) Solo com bloco rochoso; c) Solo sem bloco rochoso.

Figura 4.29 Modos de ruptura de um grão de quartzo comprimido diametralmente.

Figura 4.30 Mecanismo de quebra de grãos: a) Grão fissurado sob carregamento; b) Ensaio de tração por compressão diametral.

Figura 4.31 Microscopia de grãos de solo residual. Detalhe de micro-fissuras aleatórias.

Figura 4.32 Montagem do ensaio de compressão diametral no elemento: a) Coleta das forças nos contatos; b) Forças resultantes segundo a direção da máxima força, e normal a esta; c) Forças do ensaio; d) Novos elementos gerados.

Figura 4.33 Adensamento de solo com grãos fracos: a) Configuração inicial; b,c,d) Estágios do ensaio; e) Configuração final; f) Configuração final no caso sem grãos fracos.

Figura 4.34 Geometria idealizada do menisco: a) Quase-contato; b) Contato estrito; c) Super-contato.

Figura 4.35 a) Força capilar no menisco; b) Força capilar em função do ângulo de molhado.

Figura 4.36 Processos de transferência de massa partícula-menisco-poro. 
Figura 4.37 Rede de fluxo baseada nos contatos entre elementos. 149

Figura 4.38 Conectividade de fluxo entre meniscos e partículas. 150

Figura 4.39 Evolução da espessura da película de água aderida numa 151 partícula de raio $R=0,50 \mathrm{~mm}$ em função da sucção, segundo o modelo de Kovacs (1981).

Figura 4.40 Rede de fluxo em bolsões de grumos argilosos. 152

Figura 4.41 Fusão de meniscos. 154

Figura 4.42 Esquema do acoplamento fluxo-mecânico. 155

Figura 4.43 Ciclo de cálculo no modelo de fluxo. 156

Figura 4.44 Estrutura de dados da rede de fluxo. 158

Figura 4.45 Ensaio edométrico com umedecimento: a) Condição inicial; 160 b,c,d) Seqüência do ensaio.

Figura 4.46 Substituição do $\mathrm{Mg}^{2}$ por $\mathrm{Al}^{3}$ causando a carga negativa da 165 partícula.

Figura 4.47 Expansão de montmorilonita de cálcio e sódio. 165

Figura 4.48 Aparelho de pressão de ar para realização do ensaio de 167 inchamento com controle da sucção (Jimenez Salas \& Alpañes, 1975).

Figura 4.49 Pressão de inchamento de uma amostra de solo em função da sucção para três valores de umidade inicial diferentes (Jimenez Salas \& Alpañes, 1975).

Figura 4.50 Inchamento livre de uma amostra de solo em função da sucção (Jimenez Salas \& Alpañes, 1975).

Figura 4.51 Ensaio de expansão confinada para 20 e $60 \mathrm{kPa}$ : a) Escala normal; b) Escala logarítmica (adaptado de Jucá e Pontes Filho, 1997).

Figura 4.52 Superfície de estado idealizada para solos não saturados. 171

Figura 4.53 Modelo comportamental de solos com dupla estrutura. 172

Figura 4.54 a) Relação entre o espaçamento interpartículas e a pressão de inchamento para uma montmorilonita (Warkentin et al, 1957); b) Deformações volumétricas elásticas na microestrutura segundo o modelo de dupla estrutura.

Figura 4.55 Barreira contra infiltração. Condição inicial $(\mathrm{Sr}=4,92 \%)$. 177

Figura 4.56 Barreira de material não expansivo $(\mathrm{Sr}=5,96 \%)$.

$\begin{array}{lll}\text { Figura } 4.57 & \text { Barreira de material expansivo ( } \mathrm{Sr}=4,91 \%) . & 178\end{array}$

Figura 4.58 Utilidades incorporadas na interface gráfica: a) Indicador do número de ciclos e tempo de cálculo e botões para ativar a visualização da númeração de elementos, links e paredes; b) Matriz indicadora de quantidade e atributos de elementos e links.

Figura 4.59 Mudanças na interface gráfica do programa de análise: a) Interface do programa Sand original; b) Interface do programa DEMlib-RSM.

Figura 4.60 a) Visualização da numeração dos elementos discretos; b) Visualização da numeração dos contatos.

Figura 4.61 Visualização das magnitudes físicas nos elementos discretos: a) Velocidades; b) Forças; c) Deslocamentos.

\section{Capítulo 5}

$\begin{array}{lll}\text { Figura 5.1 Esquema do ensaio de cisalhamento direto e forças atuantes. } & 187\end{array}$

Figura 5.2 Técnica de upscaling. 
Figura 5.3 Simulação de quebra de grãos sob cisalhamento (Lobo-Guerrero \& Vallejo, 2005).

Figura 5.4 Simulação do ensaio de cisalhamento direto (Zhang \& Thornton, 193 2007).

Figura 5.5 Resultados do ensaio: a) Curva tensão $x$ deslocamento horizontal;

b) Curva deslocamento vertical $x$ deslocamento horizontal (Zhang \& Thornton, 2007).

Figura 5.6 Parâmetros do sistema de contato entre elementos.

Figura 5.7 Superposição (s) de contato entre elementos discretos: a) Entre discos; b) Entre disco e parede.

Figura 5.8 Componentes da resistência de areias (Rowe, 1962). 197

Figura 5.9 Upscaling. Deslocamento e discretização da curva 199 granulométrica.

Figura 5.10 Ensaio de cisalhamento direto em amostras de solo graduado e uniforme: a) Curva tensão cisalhante $\mathrm{x}$ deslocamento horizontal; b) Curva deslocamento vertical $x$ deslocamento horizontal.

Figura 5.11 Ensaio de cisalhamento direto em amostra uniforme: a) Arranjo inicial; b) Detalhe do arranjo denso e estável; c) Detalhe do plano de cisalhamento.

Figura 5.12 Técnica dos elementos fictícios: a) Amostra de solo inicial, com os elementos fictícios; b) Configuração final da amostra adensada após a retirada dos elementos fictícios.

Figura 5.13 a) Ensaio de cisalhamento direto com as caixas inferior e superior separadas; b) Detalhe da disposição do solo na zona da abertura das caixas.

Figura 5.14 Ensaio de cisalhamento direto para caixa fechada e aberta: a) Curva tensão cisalhante $\mathrm{x}$ deslocamento horizontal; b) Curva deslocamento vertical $x$ deslocamento horizontal.

Figura 5.15 a) Fuga de material pela separação da caixa durante o cisalhamento da amostra de solo; b) Detalhe da fuga de material e o volume adicional da caixa.

Figura 5.16 Ensaio de cisalhamento direto executado com a parte inferior da caixa fixa, e a superior deslocando.

Figura 5.17 Ensaio de cisalhamento direto executado com a parte superior da caixa fixa, e a inferior deslocando.

Figura 5.18 Forças de atrito nas paredes da caixa superior durante o ensaio.

201

Figura 5.19 Resposta do ensaio de cisalhamento direto: a) Curva tensão $x$ deslocamento horizontal; b) Curva deslocamento vertical $x$ deslocamento horizontal.

Figura 5.20 Resposta da simulação do ensaio de cisalhamento direto com tensão vertical igual a $100 \mathrm{kPa}$ : a) Curva tensão $\mathrm{x}$ deslocamento horizontal; b) Curva deslocamento vertical $\mathrm{x}$ deslocamento horizontal.

Figura 5.21 Resposta da simulação do ensaio de cisalhamento direto com tensão vertical igual a $300 \mathrm{kPa}$ : a) Curva tensão $\mathrm{x}$ deslocamento horizontal; b) Curva deslocamento vertical $\mathrm{x}$ deslocamento horizontal.

Figura 5.22 Resposta comparativa da simulação do ensaio de cisalhamento direto com tensão vertical igual a $600 \mathrm{kPa}$ : a) Curva tensão $x$ deslocamento horizontal; b) Curva deslocamento vertical $x$ deslocamento horizontal. 
Figura 5.23 Resposta comparativa da simulação do ensaio de cisalhamento direto com tensão vertical igual a $1000 \mathrm{kPa}$ : a) Curva tensão $x$ deslocamento horizontal; b) Curva deslocamento vertical $x$ deslocamento horizontal.

Figura 5.24 Resposta comparativa da simulação do ensaio de cisalhamento direto com tensão vertical igual a $1500 \mathrm{kPa}$ : a) Curva tensão $x$ deslocamento horizontal; b) Curva deslocamento vertical $x$ deslocamento horizontal.

Figura 5.25 Envoltória de resistência de pico.

218

Figura 5.26 Evolução do índice de vazios e durante o cisalhamento. 219

Figura 5.27 Ensaio de cisalhamento direto. Formação da área de cisalhamento no interior da amostra de solo: a) Configuração inicial; b) c) Amostra cisalhada.

Figura 5.28 Componentes da resistência de areias (Rowe, 1962).

Figura 5.29 Evolução do ângulo de atrito com o índice de vazios. 224

Figura 5.30 Curvas granulométricas de amostras com 3 e 9 tamanhos de grãos diferentes, a as suas correspondentes curvas de classificação pelo SUCS.

Figura 5.31 Resposta da simulação do ensaio de cisalhamento direto com tensão vertical de $300 \mathrm{kPa}$ para amostras muito densas com 3 e 9 tamanhos diferentes de grãos: a) Curva tensão $x$ deslocamento horizontal; b) Curva deslocamento vertical $\mathrm{x}$ deslocamento horizontal.

Figura 5.32 Elemento de geometria especial formado a partir da ligação rígida de dois elementos circulares.

Figura 5.33 Resposta da simulação do ensaio de cisalhamento direto com tensão vertical de $300 \mathrm{kPa}$ para amostras muito densas com 9 tamanhos diferentes de grãos, com e sem grãos especiais: a) Curva tensão $x$ deslocamento horizontal; b) Curva deslocamento vertical $x$ deslocamento horizontal.

\section{Capítulo 6}

Figura 6.1 Detalhe da quebra de grãos: a) Instante da quebra de dois grãos;

Figura 6.2 Quebra de grãos em amostra densa durante o ensaio edométrico.

a) Curva de adensamento de solo com quebra de grãos; b)

Figura 6.4 Histórico de quebra de grãos durante o ensaio de cisalhamento

Figura 6.5 Histórico de quebra de grãos durante o ensaio de cisalhamento

Figura 6.6 Histórico de quebra de grãos durante o ensaio de cisalhamento direto, sob uma tensão vertical de $1500 \mathrm{kPa}$.

Figura 6.7 Número total de quebras nas amostras em função da tensão

Figura 6.8 Simulação do ensaio de cisalhamento direto em amostra muito fofa com quebra de grãos, para tensão vertical de $600 \mathrm{kPa}$ : a) Curva tensão $\mathrm{x}$ deslocamento horizontal; b) Curva deslocamento vertical $x$ deslocamento horizontal. 
Figura 6.9 Simulação do ensaio de cisalhamento direto em amostra fofa com quebra de grãos, para tensão vertical de $600 \mathrm{kPa}$ : a) Curva tensão $x$ deslocamento horizontal; b) Curva deslocamento vertical $x$ deslocamento horizontal.

Figura 6.10 Simulação do ensaio de cisalhamento direto em amostra densa com quebra de grãos, para tensão vertical de 600kPa: a) Curva tensão $\mathrm{x}$ deslocamento horizontal; b) Curva deslocamento vertical $x$ deslocamento horizontal.

Figura 6.11 Simulação do ensaio de cisalhamento direto em amostra muito densa com quebra de grãos, para tensão vertical de $600 \mathrm{kPa}$ : a) Curva tensão $\mathrm{x}$ deslocamento horizontal; b) Curva deslocamento vertical $x$ deslocamento horizontal.

Figura 6.12 Simulação do ensaio de cisalhamento direto em amostra muito fofa com quebra de grãos, para tensão vertical de $1000 \mathrm{kPa}$ : a) Curva tensão $x$ deslocamento horizontal; b) Curva deslocamento vertical $\mathrm{x}$ deslocamento horizontal.

Figura 6.13 Simulação do ensaio de cisalhamento direto em amostra fofa com quebra de grãos, para tensão vertical de $1000 \mathrm{kPa}$ : a) Curva tensão $\mathrm{x}$ deslocamento horizontal; b) Curva deslocamento vertical $x$ deslocamento horizontal.

Figura 6.14 Simulação do ensaio de cisalhamento direto em amostra densa com quebra de grãos, para tensão vertical de $1000 \mathrm{kPa}$ : a) Curva tensão $x$ deslocamento horizontal; b) Curva deslocamento vertical $x$ deslocamento horizontal.

Figura 6.15 Simulação do ensaio de cisalhamento direto em amostra muito densa com quebra de grãos, para tensão vertical de $1000 \mathrm{kPa}$ : a) Curva tensão $x$ deslocamento horizontal; b) Curva deslocamento vertical $x$ deslocamento horizontal.

Figura 6.16 Simulação do ensaio de cisalhamento direto em amostra muito fofa com quebra de grãos, para tensão vertical de $1500 \mathrm{kPa}$ : a) Curva tensão $x$ deslocamento horizontal; b) Curva deslocamento vertical $\mathrm{x}$ deslocamento horizontal.

Figura 6.17 Simulação do ensaio de cisalhamento direto em amostra fofa com quebra de grãos, para tensão vertical de $1500 \mathrm{kPa}$ : a) Curva tensão $x$ deslocamento horizontal; b) Curva deslocamento vertical $x$ deslocamento horizontal.

Figura 6.18 Simulação do ensaio de cisalhamento direto em amostra densa com quebra de grãos, para tensão vertical de $1500 \mathrm{kPa}$ : a) Curva tensão $x$ deslocamento horizontal; b) Curva deslocamento vertical $x$ deslocamento horizontal.

Figura 6.19 Simulação do ensaio de cisalhamento direto em amostra muito densa com quebra de grãos, para tensão vertical de $1500 \mathrm{kPa}$ : a) Curva tensão $x$ deslocamento horizontal; b) Curva deslocamento vertical $x$ deslocamento horizontal.

Figura 6.20 Envoltória de resistência do solo muito fofo com quebra de grãos.

Figura 6.21

Envoltória de resistência do solo fofo com quebra de grãos. grãos.

Figura 6.24 Evolução do ângulo de atrito com a tensão vertical em amostras com quebra de grãos.

Figura 6.25 Índice de vazios inicial e final dos solos com quebra de grãos cisalhados. 
Figura 6.26 Contribuição do atrito, ditatância, quebra e rearranjo de grãos na envoltória de resistencia de Mohr para ensaios drenados em areias (Lee \& Seed, 1967).

Figura 6.27 Simulação de quebra de grãos sob cisalhamento (Lobo-Guerrero \& Vallejo, 2005).

Figura 6.28 Resultados relativos à mesma amostra sem quebra: a) Ganho na resistência ao cisalhamento com o número de quebras; b) Variação no índice de vazios com o número de quebras.

Figura 6.29 a) Curvas de adensamento normalizada de solos com cimentação de grãos para uma resistência do cimento de $\mathrm{Fc}=5 \mathrm{~N}$; b) Histórico de quebra de contatos cimentados com a pressão vertical.

Figura 6.30 Evolução da tensão virtual de pré-adensamento e o índice de compressão com a porcentagem de contatos cimentados, para amostra fofa de $\mathrm{Fc}=5 \mathrm{~N}$.

Figura 6.31 a) Curvas de adensamento normalizada de solos com e sem cimentação de grãos para igual valor de $e_{0}$; b) Histórico de quebra de contatos cimentados com a pressão vertical.

Figura 6.32 Esquema de uma curva de adensamento de solos fraca e altamente cimentados.

Figura 6.33 Histórico de quebras de contatos cimentados em amostras fofas e muito fofas, para tensão vertical de 100 e $300 \mathrm{kPa}(\mathrm{Fc}=0,5 \mathrm{~N})$.

Figura 6.34 Histórico de quebras de contatos cimentados em amostras densas e muito densas, para tensão vertical de $300 \mathrm{kPa}$.

Figura 6.35 Histórico de quebras de contatos cimentados em amostras fofas e muito fofas, para tensão vertical de $600 \mathrm{kPa}$.

Figura 6.36 Histórico de quebras de contatos cimentados em amostras densas e muito densas, para tensão vertical de $600 \mathrm{kPa}$.

Figura 6.37 Histórico de quebras de contatos cimentados em amostras densas e muito densas, para tensão vertical de $1000 \mathrm{kPa}$.

Figura 6.38 Histórico de quebras de contatos cimentados em amostras densas e muito densas, para tensão vertical de $1500 \mathrm{kPa}$.

Figura 6.39 Histórico de quebras de contatos cimentados em função da tensão vertical.

Figura 6.40 Simulação do ensaio de cisalhamento direto em amostra fofa e muito fofa com cimentação de grãos, para tensão vertical de 100kPa: a) Curva tensão $x$ deslocamento horizontal; b) Curva deslocamento vertical $x$ deslocamento horizontal.

Figura 6.41 Simulação do ensaio de cisalhamento direto em amostra fofa e muito fofa com cimentação de grãos, para tensão vertical de 300kPa: a) Curva tensão $x$ deslocamento horizontal; b) Curva deslocamento vertical $x$ deslocamento horizontal.

Figura 6.42 Simulação do ensaio de cisalhamento direto em amostra densa com cimentação de grãos, para tensão vertical de $300 \mathrm{kPa}$ : a) Curva tensão $\mathrm{x}$ deslocamento horizontal; b) Curva deslocamento vertical $x$ deslocamento horizontal.

Figura 6.43 Simulação do ensaio de cisalhamento direto em amostra muito densa com cimentação de grãos, para tensão vertical de $300 \mathrm{kPa}$ : a) Curva tensão $x$ deslocamento horizontal; b) Curva deslocamento vertical $x$ deslocamento horizontal.

Figura 6.44 Simulação do ensaio de cisalhamento direto em amostra muito fofa com cimentação de grãos, para tensão vertical de $600 \mathrm{kPa}$ : a) Curva tensão $x$ deslocamento horizontal; b) Curva deslocamento vertical $x$ deslocamento horizontal. 
Figura 6.45 Simulação do ensaio de cisalhamento direto em amostra fofa com cimentação de grãos, para tensão vertical de $600 \mathrm{kPa}$ : a) Curva tensão $x$ deslocamento horizontal; b) Curva deslocamento vertical $x$ deslocamento horizontal.

Figura 6.46 Simulação do ensaio de cisalhamento direto em amostra densa com cimentação de grãos, para tensão vertical de $600 \mathrm{kPa}$ : a) Curva tensão $\mathrm{x}$ deslocamento horizontal; b) Curva deslocamento vertical $\mathrm{x}$ deslocamento horizontal.

Figura 6.47 Simulação do ensaio de cisalhamento direto em amostra muito densa com cimentação de grãos, para tensão vertical de 600kPa: a) Curva tensão $x$ deslocamento horizontal; b) Curva deslocamento vertical $x$ deslocamento horizontal.

Figura 6.48 Simulação do ensaio de cisalhamento direto em amostra densa com cimentação de grãos, para tensão vertical de $1000 \mathrm{kPa}$ : a) Curva tensão $\mathrm{x}$ deslocamento horizontal; b) Curva deslocamento vertical $\mathrm{x}$ deslocamento horizontal.

Figura 6.49 Simulação do ensaio de cisalhamento direto em amostra muito densa com cimentação de grãos, para tensão vertical de 1000kPa: a) Curva tensão $x$ deslocamento horizontal; b) Curva deslocamento vertical $x$ deslocamento horizontal.

Figura 6.50 Simulação do ensaio de cisalhamento direto em amostra densa com cimentação de grãos, para tensão vertical de $1500 \mathrm{kPa}$ : a) Curva tensão $\mathrm{x}$ deslocamento horizontal; b) Curva deslocamento vertical $\mathrm{x}$ deslocamento horizontal.

Figura 6.51 Simulação do ensaio de cisalhamento direto em amostra muito densa com cimentação de grãos, para tensão vertical de 1500kPa: a) Curva tensão $x$ deslocamento horizontal; b) Curva deslocamento vertical $x$ deslocamento horizontal.

Figura 6.52 Envoltórias de resistência para solos com cimentação de grãos: a) Solo muito fofo; b) Solo fofo.

Figura 6.53 Envoltórias de resistência para solos com cimentação de grãos: a) Solo denso; b) Solo muito denso.

Figura 6.54 a) Esquema dos modos de cisalhamento de solos estruturados; b) Envoltória de resistência em solo residual (Vargas, 1974).

Figura 6.55 Ensaio triaxial de calcarenita natural (Coop \& Atkinson, 1993).

Figura 6.56 Amostra de solo com grãos especiais formados pela junção rígida de dois elementos discretos.

Figura 6.57 Curva de adensamento de amostra muito fofa com e sem grãos especiais.

Figura 6.58 Simulação do ensaio de cisalhamento direto em amostra fofa com grãos de geometria especial, para tensão vertical de $300 \mathrm{kPa}$ : a) Curva tensão $x$ deslocamento horizontal; b) Curva deslocamento vertical $\mathrm{x}$ deslocamento horizontal.

Figura 6.59 Simulação do ensaio de cisalhamento direto em amostra densa com grãos de geometria especial, para tensão vertical de $300 \mathrm{kPa}$ : a) Curva tensão $x$ deslocamento horizontal; b) Curva deslocamento vertical $x$ deslocamento horizontal.

Figura 6.60 Simulação do ensaio de cisalhamento direto em amostra fofa com grãos de geometria especial, para tensão vertical de $600 \mathrm{kPa}$ : a) Curva tensão $x$ deslocamento horizontal; b) Curva deslocamento vertical $x$ deslocamento horizontal.

Figura 6.61 Simulação do ensaio de cisalhamento direto em amostra densa com grãos de geometria especial, para tensão vertical de $600 \mathrm{kPa}$ : a) Curva tensão $x$ deslocamento horizontal; b) Curva deslocamento vertical $x$ deslocamento horizontal. 
Figura 6.62 Envoltória de resistência para amostras com grãos especiais. 303

Figura 6.63 Amostra com grumos argilosos. 305

Figura 6.64 Curva de adensamento em amostras com grumos argilosos de 306 diferente módulo volumétrico Kv.

Figura 6.65 Ensaio de expansão confinada (carga vertical de 100 e $300 \mathrm{kPa}$ ) em amostra de argila expansiva montada com grumos ativos.

Figura 6.66 Ensaio de expansão confinada para 20 e $60 \mathrm{kPa}$ (adaptado de Jucá e Pontes Filho, 1997).

Figura 6.67 a) Evolução do índice de compressão com o módulo volumétrico $\mathrm{Kv}$; b) Evolução da tensão virtual de pré-adensamento com o módulo volumétrico $\mathrm{Kv}$.

Figura 6.68 Simulação do ensaio de cisalhamento direto em amostra fofa com grumos argilosos, para tensão vertical de $300 \mathrm{kPa}$ : a) Curva tensão $x$ deslocamento horizontal; b) Curva deslocamento vertical $x$ deslocamento horizontal.

Figura 6.69 Simulação do ensaio de cisalhamento direto em amostra densa com grumos argilosos, para tensão vertical de 300kPa: a) Curva tensão $x$ deslocamento horizontal; b) Curva deslocamento vertical $x$ deslocamento horizontal.

Figura 6.70 Simulação do ensaio de cisalhamento direto em amostra fofa com grumos argilosos, para tensão vertical de $600 \mathrm{kPa}$ : a) Curva tensão $x$ deslocamento horizontal; b) Curva deslocamento vertical $x$ deslocamento horizontal.

Figura 6.71 Simulação do ensaio de cisalhamento direto em amostra densa com grumos argilosos, para tensão vertical de 600kPa: a) Curva tensão $\mathrm{x}$ deslocamento horizontal; b) Curva deslocamento vertical $x$ deslocamento horizontal.

Figura 6.72 Simulação do ensaio de cisalhamento direto em amostra densa com grumos argilosos plásticos, para tensão vertical de $300 \mathrm{kPa}$ : a) Curva tensão $x$ deslocamento horizontal; b) Curva deslocamento vertical $x$ deslocamento horizontal.

Figura 6.73 Simulação do ensaio de cisalhamento direto em amostra densa com grumos argilosos plásticos, para tensão vertical de $600 \mathrm{kPa}$ : a) Curva tensão $x$ deslocamento horizontal; b) Curva deslocamento vertical $x$ deslocamento horizontal.

Figura 6.74 Envoltória de resistência para amostras com grumos argilosos: a) Solo fofo; b) Solo denso.

Figura 6.75 Resultados de ensaios triaxiais drenados em amostras saturadas de um solo residual maduro argilo-arenoso (Toll \& Ong, 2003).

Figura 6.76 a) Amostra de solo na condição não saturada. Mapa de distribuição da sucção na amostra; b) Detalhe do mapa das sucções médias nos grãos.

Figura 6.77 Curva de adensamento de amostras densas não saturadas.

Figura 6.78 Curvas de compressão e adensamento de uma amostra densa não saturada com trajetória de umedecimento súbito para simulação de colapso.

Figura 6.79 Ensaio de compressão isotrópica para solo saturado e não saturado: a) curvas de compressão isotrópica no plano $v$ - $\ln p$; b) curva de escoamento no plano $(p, s)$ (modificado de Alonso et al, 1990).

Figura $6.80 \quad$ a) Ensaio edométrico em solo saturado e com umidade natural (Jennings \& Knight, 1957); b) Colapso induzido por saturação (Vargas, 1992). 
Figura 6.81 Parâmetros de adensamento em amostras densas não saturadas:

a) Tensão virtual de pré-adensamento; b) Índice de compressão.

Figura 6.82 Simulação do ensaio de cisalhamento direto em amostra densa com sucção controlada (25 e $50 \mathrm{kPa})$, para tensão vertical de 300kPa: a) Curva tensão $x$ deslocamento horizontal; b) Curva deslocamento vertical $x$ deslocamento horizontal.

Figura 6.83 Simulação do ensaio de cisalhamento direto em amostra densa com sucção controlada $(75,100$ e $150 \mathrm{kPa})$, para tensão vertical de 300kPa: a) Curva tensão $x$ deslocamento horizontal; b) Curva deslocamento vertical $x$ deslocamento horizontal.

Figura 6.84 Simulação do ensaio de cisalhamento direto em amostra densa com sucção controlada (25 e $50 \mathrm{kPa}$ ), para tensão vertical de $600 \mathrm{kPa}$ : a) Curva tensão $\mathrm{x}$ deslocamento horizontal; b) Curva deslocamento vertical $x$ deslocamento horizontal.

Figura 6.85 Simulação do ensaio de cisalhamento direto em amostra densa com sucção controlada $(75,100$ e $150 \mathrm{kPa})$, para tensão vertical de 600kPa: a) Curva tensão $x$ deslocamento horizontal; b) Curva deslocamento vertical $x$ deslocamento horizontal.

Figura 6.86 Envoltória de resistência de amostra densa com sucção controlada: a) No plano $\sigma-\tau$; b) No plano $s-\tau$.

Figura 6.87 Evolução dos parâmetros de resistência não saturada com a sucção aplicada: a) coesão aparente $c:$ b) ângulo de atrito $\phi^{\prime}$; c) ângulo de resistência devido à sucção $\phi_{b}$.

Figura 6.88 Curva característica da amostra densa para 300 e $600 \mathrm{kPa}$ de tensão vertical.

Figura 6.89 a) Evolução da coesão aparente com a sucção; b) Envoltória de resistência não linear para estados não saturados (Lopes et al, 2007).

Figura 6.90 Curva de adensamento de amostras densas com grumos e sucção aplicada.

Figura 6.91 Simulação do ensaio de cisalhamento direto em amostra densa com sucção controlada $(50 \mathrm{kPa})$ e matriz argilosa, para tensão vertical de $300 \mathrm{kPa}$ : a) Curva tensão $\mathrm{x}$ deslocamento horizontal; b) Curva deslocamento vertical $x$ deslocamento horizontal.

Figura 6.92 Simulação do ensaio de cisalhamento direto em amostra densa com sucção controlada $(50 \mathrm{kPa})$ e matriz argilosa, para tensão vertical de $600 \mathrm{kPa}$ : a) Curva tensão $\mathrm{x}$ deslocamento horizontal; b) Curva deslocamento vertical $x$ deslocamento horizontal.

Figura 6.93 Envoltória de resistência da amostra densa com sucção controlada $(50 \mathrm{kPa})$ e matriz argilosa.

\section{Capítulo 7}

Figura 7.1 Comportamento observado de solos residuais no ensaio triaxial:

Figura 7.2 a) Características físicas de solo laterítico $(1 \mathrm{~m})$ e saprolítico $(5 \mathrm{~m})$;

Figura 7.3 Ensaio triaxial com sucção controlada: a) solo jovem; b) solo maduro (Futai et al, 2004).

Figura 7.4 Ensaio de cisalhamento direto em solo residual de folhelho da região de KwaZulu Natal, Sudáfrica (Brenner et al, 1997). 
Figura 7.5 Resultados de ensaios triaxiais drenados com amostras saturadas; a) Solo residual jovem; b) Solo residual maduro.

Figura 7.6 Resultados de ensaios triaxiais com sucção controlada em solo residual jovem, para confinamentos de 50, 100 e 200kPa: a) $\mathrm{s}=$ $80 \mathrm{kPa}$; b) $\mathrm{s}=320 \mathrm{kPa}$ (Reis \& Vilar, 2004).

Figura 7.7 Resultados de ensaios triaxiais com sucção controlada em solo residual maduro, para confinamentos de 50 e $200 \mathrm{kPa}$ : a) $\mathrm{s}=$ $80 \mathrm{kPa}$; b) $\mathrm{s}=320 \mathrm{kPa}$ (Reis \& Vilar, 2004).

Figura $7.8 \quad$ a) Curvas de adensamento normalizadas das amostras de solo residual jovem. Em detalhe a evolução no tempo da variação de altura da amostra "Jovem V". b) Parâmetros de compressibilidade.

Figura 7.9 Histórico de quebras durante o ensaio edométrico em amostras de solo residual jovem: a) Quebra de cimentação; b) Quebra de grãos.

Figura 7.10 Detalhe de amostra de solo residual jovem. 360

Figura 7.11 Histórico de quebras de cimentação e de grãos sob cisalhamento para as sete amostras de solo residual jovem.

Figura 7.12 Simulação do ensaio de cisalhamento direto em amostra de solo residual jovem $\mathrm{N}^{\circ} 1$ e $\mathrm{N}^{\circ} 2$, para tensão vertical de $300 \mathrm{kPa}$ e sucção de $50 \mathrm{kPa}$ : a) Curva tensão $\mathrm{x}$ deslocamento horizontal; b) Curva deslocamento vertical $x$ deslocamento horizontal.

Figura 7.13 Simulação do ensaio de cisalhamento direto em amostra de solo residual jovem $\mathrm{N}^{\circ} 3$ e $\mathrm{N}^{\circ} 4$, para tensão vertical de $300 \mathrm{kPa}$ e sucção de 50kPa: a) Curva tensão $x$ deslocamento horizontal; b) Curva deslocamento vertical $\mathrm{x}$ deslocamento horizontal.

Figura 7.14 Simulação do ensaio de cisalhamento direto em amostra de solo residual jovem $\mathrm{N}^{\circ} 5, \mathrm{~N}^{\circ} 6$ e $\mathrm{N}^{\circ} 7$, para tensão vertical de $300 \mathrm{kPa}$ e sucção de 50kPa: a) Curva tensão $x$ deslocamento horizontal; b) Curva deslocamento vertical $x$ deslocamento horizontal.

Figura 7.15 a) Curvas de adensamento normalizadas das amostras de solo residual maduro; b) Parâmetros de compressibilidade.

Figura 7.16 Detalhe de amostra de solo residual maduro.

Figura 7.17 Simulação do ensaio de cisalhamento direto em amostra de solo 371 residual maduro $\mathrm{N}^{\circ} 1, \mathrm{~N}^{\circ} 2$ e $\mathrm{N}^{\circ} 3$, para tensão vertical de $300 \mathrm{kPa}$ e sucção de $50 \mathrm{kPa}$ : a) Curva tensão $x$ deslocamento horizontal; b) Curva deslocamento vertical $x$ deslocamento horizontal. 


\section{Lista de Tabelas}

\section{Capítulo 3}

Tabela 3.1 Alguns modelos constitutivos elasto-plásticos básicos (Ibañez, 2003). 75

Tabela 3.2 Alguns modelos constitutivos elasto-plásticos avançados (Ibañez, 75 2003).

Tabela 3.3 Alguns modelos para solos não saturados e estruturados (Ibañez, 76 2003).

\section{Capítulo 4}

Tabela 4.1 Valores típicos de Atividade (Nelson \& Miller, 1992). 162

Tabela 4.2 Propriedades do solo que influenciam o potencial de expansão - 163 contração (Nelson \& Miller, 1992).

$\begin{array}{lll}\text { Tabela 4.3 } & \text { Argilas mais comuns encontradas. } & 164\end{array}$

Tabela 4.4 Tratamento de cores aplicado aos elementos discretos. 182

$\begin{array}{lll}\text { Tabela 4.5 } & \text { Tratamento de cores aplicado aos contatos. } & 183\end{array}$

Tabela 4.6 Tratamento de cores aplicado aos elementos parede. 183

\section{Capítulo 5}

Tabela 5.1 Índice de vazios inicial das amostras de solo usadas na validação. 211

Tabela 5.2 Índice de vazios inicial e final das amostras ensaiadas. 218

Tabela 5.3 Dados granulométricos da amostra com três tamanhos de grãos 226 diferentes.

Tabela 5.4 Dados granulométricos da amostra com nove tamanhos de grãos 227 diferentes.

\section{Capítulo 6}

Tabela 6.1 Campanha de ensaios para simulação da quebra de grãos. Valor inicial e final do índice de vazios 'e' em cada ensaio (Sc: resistência do grão).

Tabela 6.2 Valores da tensão virtual de pré-adensamento e do índice de 268 compressão das amostras ensaiadas.

Tabela 6.3 Campanha de ensaios para simulação da cimentação de grãos. 272 Valor inicial e final do índice de vazios 'e' em cada ensaio (Fc: resistência do cimento).

Tabela 6.4 Campanha de ensaios para simulação de solos com grãos de geometria diferenciada. Valor inicial e final do índice de vazios 'e' em cada ensaio.

Tabela 6.5 Campanha de ensaios para simulação de solos com grumos argilosos. Valor inicial e final do índice de vazios 'e' em cada ensaio.

Tabela 6.6 Variação do ângulo de atrito em amostras com grumos argilosos. 321

Tabela 6.7 Campanha de ensaios de cisalhamento com sucção controlada em 329 amostras densas. Valor inicial e final do índice de vazios 'e' em cada ensaio.

Tabela 6.8 Campanha de ensaios para simulação da presença de matriz argilosa com sucção controlada. Valor inicial e final do índice de vazios 'e' em cada ensaio.

\section{Capítulo 7}

Tabela 7.1 Amostras discretas para a simulação de solos residuais jovens. 357

Tabela 7.2 Amostras discretas para a simulação de solos residuais maduros. 369 


\section{Lista de símbolos}

\begin{tabular}{|c|c|}
\hline$A$ & área \\
\hline$A_{c}$ & atividade de minerais argilosos \\
\hline$c$ & amortecimento \\
\hline$c_{a p}$ & coesão aparente \\
\hline$c^{\prime}$ & coesão efetiva \\
\hline Cn & amortecimento normal \\
\hline Cs & amortecimento tangencial \\
\hline$C_{r}$ & coeficiênte de adensamento \\
\hline$C_{c}$ & índice de compressão \\
\hline$e$ & Índice de vazios \\
\hline$E$ & energia \\
\hline$e_{0}$ & índice de vazios inicial \\
\hline$F$ & força \\
\hline FC & resistência do cimento \\
\hline$F_{w}$ & força capilar \\
\hline$J_{\mu}$ & função de Bessel \\
\hline k & rigidez \\
\hline$k n$ & rigidez normal \\
\hline$k s$ & rigidez tangencial \\
\hline$k_{r}$ & permeabilidade radial \\
\hline$K, K_{v}$ & módulo volumétrico \\
\hline M & momento \\
\hline$m$ & massa \\
\hline$m_{w}$ & massa dos elementos parede \\
\hline$N$ & esforço normal \\
\hline$N, F n$ & forças normais \\
\hline$Q$ & esforço cisalhante \\
\hline Sc & resistência à quebra dos grãos \\
\hline$p$ & tensão liquida \\
\hline$p_{a}$ & pressão de ar \\
\hline$p_{w}$ & pressão de água \\
\hline$q$ & tensão desviadora \\
\hline$Q$ & vazão \\
\hline$r$ & raio \\
\hline Sr & grau de saturação \\
\hline$s$ & sucção \\
\hline$t$ & tempo \\
\hline$T, F s$ & forças cisalhantes \\
\hline$u, v$ & velocidade \\
\hline$U r$ & grau de adensamento \\
\hline$V$ & volume \\
\hline
\end{tabular}




\section{Lista de símbolos gregos}

$\begin{array}{ll}\alpha & \text { coeficiênte de proporcionalidade } \\ \beta & \text { compressibilidade da água } \\ \Delta t & \text { passo de tempo } \\ \delta_{r} & \text { deslocamento radial } \\ \varepsilon_{r r} & \text { deformação radial } \\ \varepsilon_{\theta \theta} & \text { deformação angular } \\ \varepsilon_{v} & \text { deformação volumétrica } \\ \varepsilon_{r \theta} & \text { deformação cisalhante } \\ \gamma_{w} & \text { peso unitário da água } \\ \mu & \text { fator de amortecimento } \\ \eta_{w} & \text { viscosidade da água } \\ \phi^{\prime} & \text { ângulo de atrito efetivo } \\ \phi_{b} & \text { ângulo de resistência devido à sucção } \\ \theta & \text { umidade volumétrica } \\ \theta & \text { ângulo de molhado } \\ \tau & \text { tensão cisalhante } \\ \sigma^{\prime} & \text { tensão normal efetiva } \\ \sigma_{O C}^{\prime} & \text { tensão virtual de pré-adensamento } \\ & \end{array}$

